\title{
Improving the Outcomes of Breast Cancer in China: Physicians' Beliefs, Recommendations, and Practices for Breast Cancer Screening
}

\author{
Tsu-Yin Wu${ }^{1}$, Vedhika Raghunathan ${ }^{2}$, Jianguo Shi ${ }^{3}$, Wang $\mathrm{Hua}^{4}$, Wang $\mathrm{Yu}^{4}$, \\ Abby Deng 5
}

${ }^{1}$ Center for Health Disparities Innovation and Studies, Eastern Michigan University, Ypsilanti, MI, United States. ${ }^{2}$ College of Literature, Science and the Arts, University of Michigan, Ann Arbor, MI, United States. ${ }^{3}$ Fourth Military Medical University, Xi'An, Shaanxi Province, China. ${ }^{4} X i$ 'An Cancer Rehabilitation Association, Xi'An, Shaanxi Province, China. ${ }^{5}$ School of Nursing, University of Michigan, Ann Arbor, MI, United States.

\begin{abstract}
Objective: Physicians play a key role in performing and referring patients for cancer screening. A paucity of data exists for breast cancer screening (BCS) recommendations, demographic characteristics, screening practices, and barriers of screening among physicians. The purpose of this project is to examine physicians' characteristics, practices, and beliefs about BCS recommendations and its barriers. Methods: The study used a descriptive correlational design and 110 surveys were completed. Data was analyzed using descriptive and inferential statistics generated with Statistical Packages for Sciences (SPSS) 26.0 version. Results: Most of the surveyed Chinese physicians worked in the community, were females, and between 30-39 years of age. Participants reported working in collaboration on numerous aspects of BCS, and also reported the recommendation of starting screening at younger ages in contrast to existing guidelines. A higher percentage of participants recommended more clinical breast exams compared to mammograms or ultrasounds. Several perceived barriers in working with patients and lower physician comfort levels with aspects of BCS were identified. Graduate degree-holding physicians reported higher physician comfort levels, and lower screening and follow-up practice. Increased familiarity with screening guidelines resulted in higher screening and follow-up practice but also higher physician-patient barrier scores. Increased perceived importance in using guidelines correlated to higher screening and follow-up practice scores. Conclusion: The results of this study point to the potential utility and importance in understanding the demographic factors that influence physician beliefs and practices. Results also highlighted the need for evidence-based guidelines for physician education and culturally tailored materials to address communication barriers and physician comfort. Furthermore, when studying physician screening practices and beliefs, context-specific considerations, as well as interprofessional collaboration are essential to improve patient outcomes. Physicians hold a salient role in ensuring that patients have access to cancer screening. Focusing on this group provides a critical focal point in addressing disparities in breast cancer screening and improving outcomes amongst Chinese women.
\end{abstract}

Keywords: Women's Health- preventive care- cancer screening- clinical breast exams- Mammogram- Ultrasound

\section{Introduction}

While the Chinese population is a low-risk population for breast cancer, cancer incidence and mortality have been increasing drastically, making cancer the leading cause of death since 2010 and a major public health problem [1]. In particular, breast cancer mortality rate increased by nearly $100 \%$ during the past three decades [2]. For women

Corresponding Author:

Dr. Tsu-Yin Wu

Center for Health Disparities Innovation and Studies, Eastern Michigan University, Ypsilanti, MI, United States.

Email: twu@emich.edu 
in China, trends in breast cancer incidence and mortality may differ from women in other developed Asian countries due to the changes in reproductive practices, such as lower parity and reduced breastfeeding along with the implementation of a nationwide family planning program in the 1970s [3].

Several national breast cancer screening programs have been initiated by the Chinese government since the late 2000s, such as "Chinese One Million Women Breast Cancer Screening," "Breast Cancer Screening Program," and "Countryside Women Breast and Cervical Cancer Screening Program." While these large-scale efforts are promising, the effectiveness of screening modalities employed in these screening programs is largely limited by budget constraints [4]. Additionally, breast cancer in the Chinese population indicates a younger age at diagnosis, larger tumor size, and later tumor stage. This suggests that resources in China might be better targeted at raising awareness and early detection which can have the greatest potential to make an immediate impact on the existing burden of cancer in China [5].

Currently, mammography is recommended as the primary breast cancer screening method for women with an average risk of breast cancer amongst women 45-69 years old (Level A recommendation) while clinical breast exams (CBE) are recommended as a preliminary screening method before imaging screening (Level B recommendation) [6]. Nevertheless, fewer than $25 \%$ of women reported having a mammogram in the past 5 years and $54 \%$ of women never had CBE [7].

Existing literature shows that physicians are integral public health liaisons who can educate patients about specific cancers, provide screening information, and recommend appropriate screening modalities [8]. Researchers have found when examining barriers and facilitators of breast cancer screening among Chinese American women, the only significant predictor for women reporting a mammogram was their relationship with a physician who was the source of information about mammograms [9]. While conflicting clinical practice guidelines for breast cancer screening have existed for decades, it is critical to examine how physicians implement screening guidelines in their practice. To date, there has been no analysis of demographic characteristics and screening practices of Chinese physicians who perform breast cancer screening. The purpose of this study is to use quantitative research methods to better understand physicians' knowledge on breast cancer screening (BCS) and the factors that influence their decisions to recommend BCS for Chinese women. In particular, the following objectives were examined: 1 ) current screening modalities that Chinese physicians recommend for BCS; 2) physician beliefs and comfort levels about their BCS practices; and 3) physicians' characteristics associated with BCS practices. The results of this data can serve as a baseline to improve and monitor the impact of changes in clinical practice guidelines.

\section{Materials and Methods}

\section{Study design}

This study used a descriptive cross-sectional design; data were collected from the city of Xi'An, one of the largest cities in Western China. The study protocol was reviewed and approved by the Institutional Review Board of Eastern Michigan University. The study team collaborated with Xi'An Cancer Rehabilitation Association for data collection. The study sample was comprised of physicians who practiced in internal medicine, family practice, or $\mathrm{OB} / \mathrm{GYN}$ in Xi'An. Quantitative research methods were used to examine Chinese physicians' practices and beliefs about screening recommendations for breast cancer screening, characteristics of physicians who recommend screening, and physician perceptions of barriers to screening for breast cancer.

\section{Study Instrument}

The study instrument was a survey adopted from the National Survey of Primary Care Physicians' Recommendations and Practice for Breast Cancer Screening by the National Cancer Institute [10]. The survey items consisted of questions on physicians' knowledge about breast cancer screening guidelines and their influences in clinical practice. The participants were also asked about their beliefs regarding the effectiveness of four screening tests for breast cancer (i.e., clinical breast examination (CBE), breast self-examination (BSE), mammography, and ultrasound). In addition, the participants were asked if they never, rarely, sometimes, or usually encounter specific barriers when talking with their asymptomatic average-risk patients about breast cancer screening.

Five scales were generated: 1) Screening and follow-up practice (seven items) assessed how widely practiced various breast cancer screening and follow-up practices; the higher scores indicate that the participant performs, or performs and knows others who perform these services; 2) BCS patient caseloads (three items) measured the patient caseload that physicians performed mammogram, ultrasound, and clinical breast examinations for asymptomatic and average-risk females whereas higher scores meant more patients that physicians perform these BCS modalities each month; 3) Physician-patient barriers (six items) measured the relative perceived difficulties of communication between patients and physicians; these items included time management difficulties, patients' unwillingness or difficulty in understanding breast cancer and screening, and financial difficulties of the patient that make screening difficult; higher scores correlate to a higher perception of barriers; 4) Physician comfort (three items) measured the relative ease the physician felt in telling patients about the risk factors for breast cancer, recommending screening, and conducting screening; higher scores indicated greater comfort; and 5) Recommended screening score (four items) measured whether or not the physician recommended CBEs, BSEs, mammogram, and ultrasound to female patients in asymptomatic and non-high risk populations; higher 
scores indicated physicians making more screening recommendations.

Two additional scales (six items each) measured the relative familiarity physicians had and importance physicians placed in the US Preventative Services Task Force, American Cancer Society, American College of Obstetricians \& Gynecologists, American Academy of Family Physicians, and American College of Physicians guidelines. The two scores were generated; higher scores in both scales indicated that there was higher familiarity or importance placed in these guidelines.

\section{Sample size and data collection}

In collaboration with Xi'An Cancer Rehabilitation Association, a list of physicians from local hospitals was provided. Participants were invited via email to complete an online survey with detailed instructions. To maximize the response rate, the applicants were given extensive follow-ups with the participants via email reminders. Survey items were translated to Chinese and administered to a convenience sample of 110 physicians.

\section{Data analysis}

The quantitative data was coded and entered in the Statistical Package for the Social Sciences (SPSS) version 26.0 and all the data entries were verified. Descriptive and inferential statistics were used to examine relationships between screening recommendations and physicians' characteristics. All analyses were two-sided and statistically significant at the $5 \%$ level $(\mathrm{p}<0.05)$.

\section{Results}

\section{Participant demographic characteristics}

One hundred and ten physicians in China, mostly women $(74.5 \%)$ working in clinical medicine $(72.1 \%)$ completed the survey. The mean age of participants was 40.94 years $(\mathrm{SD}=10.43$ years) with the highest percentage of participants being within 30-39 years old (41.3\%) followed by $40-49$ years old $(33.0 \%)$. The average work experience of participants was 17.34 years $(\mathrm{SD}=10.59$ years) with the highest percentage of participants having worked $11-20$ years $(38.5 \%)$ and $21-30$ years $(22.0 \%)$. Most of the participants reported working within community settings $(66.4 \%)$ followed by working in a hospital as an OB/GYN (22.7\%) and breast specialists (10.9\%). The majority of the participants had a college education $(77.3 \%$ ) while $22.5 \%$ had a graduate degree. The highest percentage of participants reported having a medical degree and practicing (68.2\%) while $15.0 \%$ of the participants reported on a director/ administrator role; $3.7 \%$ reported being faculty; and $13.0 \%$ reported working in laboratory, nursing, and administrator roles.

\section{Practices of breast cancer screening}

In terms of practicing various BCS-related services and education, physicians responded that they performed the following activities collaboratively with other physicians: prescribing mammography to diagnose breasts cancer (65\%), performing clinical breast exams (45\%), discussing the results of mammography with the patient (53\%), recommending follow-ups for the patients with positive mammography (49\%), and training patients to perform breast self-exams $(67 \%)$. The only item that physicians reported doing alone was "discussing and informing about the benefits and risks of breast cancer screening" (48\%).

More than $80 \%$ of the physicians recommended that women start breast cancer screening (BCS) between the ages of 20-25 years with the mean recommended average age to start regular BCS was 27.56 years old. While more than $90 \%$ of physicians recommended four different BCS modalities (i.e. CBE, BSE, mammography, and ultrasound), most of them did not answer what they thought the starting age for any of those screening modalities were. For most who answered, the answers were incorrect based on current screening recommendations (Table 1).

In an average month, the majority of physicians recommend 1-10 female asymptomatic non-high-risk patients for mammogram and ultrasound screenings with more patients recommended for CBEs, i.e., 24\% for 11-20 and $36 \%$ recommend 21-30 women for CBEs (Table 1).

In terms of barriers for recommending BCS in the asymptomatic non-high-risk population, several issues were reported which included, "My patient is unwilling to talk about breast cancer screening," "My patient can't fully understand what I've introduced for breast cancer screening," "My patient does not know about breast cancer screening," and "My patient doesn't consider breast cancer to be a serious threat to health." (Table 2).

When telling patients about the risk factors for breast cancer and recommending BCS, $44.5 \%$ and $59.1 \%$ of surveyed physicians were not comfortable with recommending screening to patients or conducting CBE for patients respectively (see Table 2).

\section{Physician beliefs on and practice of BCS on selected demographic variables}

Independent t-test analyses were conducted using the scores of five scales (screening and follow-up practice, BCS patient caseload, physician-patient barrier score, physician comfort, and recommended screening) across age, gender, work experience, and educational background of physicians.

The only significant difference of mean scores were across different educational background groups. Individuals with a college degree had higher mean scores (mean=5.82, $\mathrm{SD}=2.01$ ) in screening and follow-up practice scores than those with a graduate degree $($ mean=4.28, $\mathrm{SD}=3.23)(\mathrm{t}(\mathrm{df})=2.252(29.81), \mathrm{p}=.032)$. However, physicians with a graduate degree had higher comfort scores (mean=9.21, $\mathrm{SD}=1.87)$ compared to physicians with college education alone (mean $=6.72$, $\mathrm{SD}=1.46)(\mathrm{t}(\mathrm{df})=-6.923(107), \mathrm{p}=.000)($ see Table 3$)$.

\section{Correlations between beliefs, practices, and screening recommendation guidelines}

Bivariate correlation to screening and follow-up practices, BCS patient caseload score, physician-patient barrier score, physician comfort score, and recommended 
Table 1. Breast Cancer Screening (BCS) Practice: Recommendation and Performance

\begin{tabular}{|c|c|c|c|}
\hline & & Count & $\%$ \\
\hline \multirow{2}{*}{$\begin{array}{l}\text { Would you recommend breast cancer screening for female patients in asymptomatic and non-high-risk } \\
\text { populations (at their health level)? }\end{array}$} & Yes & 91 & 82.7 \\
\hline & No & 19 & 17.3 \\
\hline \multirow[t]{4}{*}{ How many women do you recommend to start regular breast cancer screening (BCS)? (Age) } & $20-25$ & 44 & 48.4 \\
\hline & $26-30$ & 33 & 36.3 \\
\hline & $31-40$ & 12 & 13.2 \\
\hline & $\geq 41$ & 2 & 2.2 \\
\hline \multicolumn{4}{|l|}{ Will you recommend the following BCS? } \\
\hline \multirow[t]{2}{*}{ Clinical breast examination } & Yes & 88 & 97.8 \\
\hline & No & 2 & 2.2 \\
\hline \multirow[t]{3}{*}{ Frequency } & Yearly & 7 & 6.3 \\
\hline & Other intervals & 7 & 9.0 \\
\hline & Did not answer & 97 & 87.4 \\
\hline \multirow[t]{2}{*}{ Breast self-examination (BSE) } & Yes & 90 & 97.8 \\
\hline & No & 2 & 2.2 \\
\hline \multirow[t]{3}{*}{ Frequency } & Monthly & 5 & 4.5 \\
\hline & Other intervals & 3 & 9.0 \\
\hline & Did not answer & 96 & 86.3 \\
\hline \multirow[t]{2}{*}{ Mammography } & Yes & 87 & 94.6 \\
\hline & No & 5 & 5.4 \\
\hline \multirow[t]{3}{*}{ Frequency } & Yearly & 11 & 9.9 \\
\hline & Other intervals & 2 & 1.8 \\
\hline & Did not answer & 98 & 88.3 \\
\hline \multirow[t]{2}{*}{ Ultrasound } & Yes & 88 & 95.7 \\
\hline & No & 4 & 4.3 \\
\hline \multirow[t]{3}{*}{ Frequency } & Monthly & 5 & 4.5 \\
\hline & Other intervals & 3 & 9.0 \\
\hline & Did not answer & 96 & 86.3 \\
\hline \multirow{6}{*}{$\begin{array}{l}\text { On average, how many female patients in the asymptomatic and non-high-risk population you performed } \\
\text { clinical breast examinations in a month? }\end{array}$} & 0 women & 18 & 16.4 \\
\hline & $1-10$ women & 11 & 10.0 \\
\hline & $11-20$ women & 26 & 23.6 \\
\hline & 21-30 women & 40 & 36.4 \\
\hline & $31-40$ women & 13 & 11.8 \\
\hline & $40+$ women & 2 & 1.8 \\
\hline \multirow[t]{6}{*}{ How many women who are asymptomatic and non-high-risk in a month do you recommend a mammogram? } & 0 women & 18 & 16.5 \\
\hline & $1-10$ women & 64 & 58.7 \\
\hline & $11-20$ women & 23 & 21.1 \\
\hline & 21-30 women & 0 & 0.0 \\
\hline & $31-40$ women & 3 & 2.8 \\
\hline & $40+$ women & 1 & 0.9 \\
\hline \multirow[t]{6}{*}{ How many women who are asymptomatic and non-high-risk in a month do you recommend for ultrasound? } & 0 women & 12 & 11.0 \\
\hline & $1-10$ women & 65 & 59.6 \\
\hline & $11-20$ women & 26 & 23.9 \\
\hline & 21-30 women & 2 & 1.8 \\
\hline & $31-40$ women & 2 & 1.8 \\
\hline & $40+$ women & 2 & 1.8 \\
\hline
\end{tabular}

screening score using Pearson's correlation tests were conducted using responses to participants' familiarity and perceived importance of breast cancer screening guidelines for diagnosis and treatment from the U.S. Preventive Services Task Force, American Cancer Society, American College of Obstetricians \& Gynecologists,
American Academy of Family Physicians, and American College of Physicians. Increased familiarity with the screening guidelines was significantly associated with higher scores for screening and follow-up practice $(\mathrm{r}=.336, \mathrm{p}=.000)$, increased physician-patient barrier $(\mathrm{r}=.234, \mathrm{p}=.016)$, and higher physician comfort scores 
Table 2. Barriers to and Comfort Level of Recommending Breast Cancer Screening

\begin{tabular}{|c|c|c|c|}
\hline & & Count & $\%$ \\
\hline \multirow{4}{*}{$\begin{array}{l}\text { When you are communicating with patients in asymptomatic and non-high-risk populations, do you not have } \\
\text { time to discuss breast cancer screening with patients? }\end{array}$} & Never & 4 & 3.7 \\
\hline & Rarely & 55 & 50.5 \\
\hline & Sometimes & 46 & 42.2 \\
\hline & Often & 4 & 3.7 \\
\hline \multirow[t]{4}{*}{ My patient is unwilling to talk about breast cancer screening } & Never & 2 & 1.8 \\
\hline & Rarely & 56 & 51.4 \\
\hline & Sometimes & 35 & 32.1 \\
\hline & Often & 16 & 14.7 \\
\hline \multirow[t]{4}{*}{ My patient can't fully understand what I've introduced for breast cancer screening } & Never & 1 & 0.9 \\
\hline & Rarely & 47 & 43.1 \\
\hline & Sometimes & 57 & 52.3 \\
\hline & Often & 4 & 3.7 \\
\hline \multirow[t]{4}{*}{ My patient does not know about breast cancer screening } & Never & 0 & 0.0 \\
\hline & Rarely & 29 & 26.9 \\
\hline & Sometimes & 50 & 46.3 \\
\hline & Often & 29 & 26.9 \\
\hline \multirow[t]{4}{*}{ My patient does not consider breast cancer to be a serious threat to health } & Never & 2 & 1.8 \\
\hline & Rarely & 50 & 45.9 \\
\hline & Sometimes & 56 & 51.4 \\
\hline & Often & 1 & 0.9 \\
\hline \multirow{4}{*}{$\begin{array}{l}\text { Medical insurance (for my patients) cannot cover the cost of examinations (such as breast cancer radiography } \\
\text { or ultrasound) }\end{array}$} & Never & 3 & 2.8 \\
\hline & Rarely & 58 & 53.2 \\
\hline & Sometimes & 44 & 40.4 \\
\hline & Often & 4 & 3.7 \\
\hline \multirow[t]{4}{*}{ Are you comfortable in telling patients about the risk factors for breast cancer? } & Very uncomfortable & 9 & 8.2 \\
\hline & Uncomfortable & 49 & 44.5 \\
\hline & Comfortable & 45 & 40.9 \\
\hline & Very comfortable & 7 & 6.4 \\
\hline \multirow[t]{4}{*}{ Do you feel at ease when recommending breast cancer screening to your patients? } & Very uncomfortable & 7 & 6.4 \\
\hline & Uncomfortable & 65 & 59.1 \\
\hline & Comfortable & 31 & 28.2 \\
\hline & Very comfortable & 7 & 6.4 \\
\hline \multirow[t]{4}{*}{ Do you feel at ease when conducting clinical breast examinations for your patients? } & Very uncomfortable & 7 & 6.4 \\
\hline & Uncomfortable & 49 & 45.0 \\
\hline & Comfortable & 47 & 43.1 \\
\hline & Very comfortable & 6 & 5.5 \\
\hline
\end{tabular}

$(\mathrm{r}=.308, \mathrm{p}=.001)$. Increased rated importance of these sources in diagnosis and treatment was significantly associated with higher screening and follow-up practice scores $(\mathrm{r}=.371, \mathrm{p}=.000)$ and physician comfort scores $(\mathrm{r}=.236, \mathrm{p}=.014)$.

In addition, scores for screening and follow-up practice were significantly positively correlated with BCS patient caseload $(\mathrm{r}=.391, \mathrm{p}=.000)$ and recommended screening scores $(\mathrm{r}=.321, \mathrm{p}=.030)$. Higher BCS patient caseload scores were additionally significantly correlated to higher recommended screening scores $(r=.449, \mathrm{p}=.000)$ while significantly correlated to lower physician-patient barrier scores $(r=-.262, \mathrm{p}=.006)$. Higher physician-patient barrier scores were also significantly correlated to lower recommended screening scores $(\mathrm{r}=-.325, \mathrm{p}=.002)$.

\section{Discussion}

To our knowledge, this is the first study that examines Chinese physicians' breast cancer screening beliefs and recommendations and their practices. This study has several important findings. First, Chinese physicians may not be fully aware of current evidence and screening guidelines which guide their breast cancer screening beliefs and recommendations. Second, the top two barriers for physicians to discuss BCS with their patients were "My patient does not know about breast cancer screening" and "They can't fully understand what I've introduced for breast cancer screening." Third, the majority of these physicians were not comfortable in prescribing various breast cancer screening modalities that include CBEs, mammograms and ultrasound for women with 
Table 3. Bivariate Analysis of Demographic Factors and Physician Belief Scores

\begin{tabular}{|c|c|c|c|c|c|c|}
\hline & $\mathrm{N}$ & $\begin{array}{l}\text { Screening and follow-up } \\
\text { practice score }\end{array}$ & $\begin{array}{l}\text { BCS patient } \\
\text { caseload score }\end{array}$ & $\begin{array}{l}\text { Physician-patient } \\
\text { barrier score }\end{array}$ & Physician comfort score & $\begin{array}{l}\text { Recommended } \\
\text { screening score }\end{array}$ \\
\hline & & Mean $( \pm \mathrm{SD})$ & Mean $( \pm \mathrm{SD})$ & Mean $( \pm \mathrm{SD})$ & Mean $( \pm \mathrm{SD})$ & Mean $( \pm \mathrm{SD})$ \\
\hline \multicolumn{7}{|l|}{ Age (years) } \\
\hline$<45$ & 72 & $5.47(2.48)$ & $7.46(2.27)$ & $15.80(1.64)$ & $7.38(1.87)$ & $3.84(0.58)$ \\
\hline$\geq 45$ & 37 & $5.41(2.36)$ & $7.86(1.99)$ & $15.39(1.93)$ & $6.92(1.69)$ & $3.90(0.40)$ \\
\hline$t(d f)$ & & $.133(105)$ & $-.905(106)$ & $1.163(105)$ & $1.257(106)$ & $-.443(87)$ \\
\hline p-value & & .894 & .368 & .248 & .212 & .659 \\
\hline \multicolumn{7}{|c|}{ Years worked } \\
\hline$<20$ & 68 & $5.44(2.44)$ & $7.50(2.22)$ & $15.78(1.68)$ & $7.46(1.86)$ & $3.86(0.59)$ \\
\hline$\geq 20$ & 42 & $5.50(2.42)$ & $8.00(2.64)$ & $15.37(1.96)$ & $6.95(1.85)$ & $3.88(0.41)$ \\
\hline$t(d f)$ & & $-.126(106)$ & $-1.060(107)$ & $1.157(106)$ & $1.397(107)$ & $-.220(88)$ \\
\hline p-value & & .900 & .292 & .250 & .165 & .826 \\
\hline \multicolumn{7}{|l|}{ Education } \\
\hline College & 85 & $5.82(2.01)$ & $7.83(1.74)$ & $15.55(1.75)$ & $6.72(1.46)$ & $3.91(0.49)$ \\
\hline Masters/ & 25 & $4.28(3.23)$ & $7.20(3.85)$ & $15.88(1.94)$ & $9.21(1.87)$ & $3.64(0.63)$ \\
\hline \multicolumn{7}{|l|}{$\mathrm{PhD}$} \\
\hline$t(d f)$ & & $2.252(29.81)$ & $.798(26.98)$ & $-.788(106)$ & $-6.923(107)$ & $1.485(16.05)$ \\
\hline p-value & & $.032^{*}$ & 0.432 & 0.432 & $.000 *$ & .157 \\
\hline \multicolumn{7}{|l|}{ Gender } \\
\hline Female & 82 & $5.44(2.38)$ & $7.69(1.99)$ & $15.57(1.67)$ & $7.41(1.32)$ & $3.89(0.52)$ \\
\hline Male & 28 & $5.52(2.61)$ & $7.68(3.32)$ & $15.78(2.14)$ & $6.86(2.92)$ & $3.79(0.54)$ \\
\hline$t(d f)$ & & -.137 (106) & $.019(33.95)$ & $-.525(106)$ & $.965(30.92)$ & $.722(88)$ \\
\hline p-value & & .891 & .985 & .600 & .342 & .472 \\
\hline
\end{tabular}

*Significant $(\mathrm{p}<0.05)$

average-risk. Finally, factors associated with physicians' practice of BCS and follow-ups include education level, familiarity of screening guidelines, and perceived importance of guidelines in diagnosis and treatment.

The educational background of physicians plays a critical role in influencing how screening and education is delivered to Chinese women. The results from this study show that higher education amongst physicians resulted in a higher comfort level in talking about and conducting breast cancer screening. Increased efforts in continuing physician education or collaboration between physicians with graduate and non-graduate degrees may be useful in increasing physicians' comfort in providing screening and follow-up services. Interestingly, non-graduate degree holding physicians had higher scores in screening and follow-up practices. One possible explanation for this could be that graduate degree-holding physicians may have additional administrative or research positions that lower their responsibilities and roles in patient communication and treatment. Focusing on encouraging and educating this subset of physicians in the importance of patient communication and treatment as well as creating support via training nurses and other healthcare practitioners within hospitals could ensure that patients have adequate access to quality breast cancer screening and education.

Additionally, familiarity with and perceived importance of BCS guidelines in diagnosis and treatment play an equally critical role. The results from this study indicate that familiarity and usage of BCS guidelines are correlated to more physicians independently communicating and performing, or collaborating with other physicians to communicate and perform BCS to patients. The importance of breast cancer screening and breast cancer screening guidelines have been validated and are largely accepted by the medical community. Physicians play an important role in ensuring that BCS is accessible to patients. Numerous studies have documented that one of the most prominent reasons for a lack of cancer screening amongst individuals is due to a lack of physician recommendation [11-13]. Additionally, there is a lower likelihood of patients receiving cancer screening if physicians have limited knowledge on screening guidelines [14]. Thus, physician education in cancer screening guidelines could serve as a critical link in ensuring increased breast cancer screening and outcomes amongst patients. In addition, providing tools for physicians to place special emphasis on the importance of adhering to screening guidelines has the potential for improving breast cancer screening rates amongst Chinese women. Interestingly, this study also shows that there is an increase in perceived physician-patient barriers amongst physicians with increased familiarity with screening guidelines from different organizations. For women at average risk for breast cancer, different medical organizations have different recommendations regarding when to start screening mammography and at what intervals to screen. Previous studies suggested there are negative consequences on clinical care when multiple guidelines exist [15]. Differences in these guidelines may explain why physicians who were more familiar 
with guidelines reported higher levels of barriers in this current study.

The results of this study indicated that the majority of the physicians reported discomfort recommending breast cancer screening to their patients, telling patients about risk factors for breast cancer, and conducting clinical breast exams for patients. These observations indicate the need and importance of culturally sensitive materials to overcome these barriers. The dissemination of culturally-relevant materials for physicians can provide specific strategies to overcome existing communication and practice barriers. Several studies across different ethnicities, including Chinese women, have shown that culture plays a critical role in cancer screening and management, particularly breast cancer [16-17]. Cultural beliefs, such as breast cancer being a taboo subject, modesty, and other stigmatizing characterizations have been attributed to the practice of breast cancer screening and treatment amongst Chinese women and immigrants [16-17]. Using tailored materials to train physicians to communicate and practice these aspects of breast cancer screening and treatment within this cultural framework may provide a solution in helping physicians to overcome challenges and barriers in their practices.

The results of this study also indicate that large percentages of physicians work collaboratively with other physicians to prescribe mammography to diagnose breasts cancer, perform clinical breast exams, discuss the results of mammography with the patient, recommend follow-ups for the patients with positive mammography, and train patients to perform breast self-exams. Interprofessional collaboration has been shown to be critical in delivering safe and effective patient care [18]. Developing professional networks and potentially expanding them to include collaboration with community partners and other healthcare workers may improve the delivery of breast cancer screening.

The results of this study also showed that physicians recommended various screenings at younger ages than current screening guidelines. This particular behavior could be the result of a younger age at onset of breast cancer in China compared to other Western countries [19]. Additionally, the results of this study indicated that mammogram is not frequently recommended while CBE is recommended more frequently. This may be the result of challenges physicians and patients in China face due to lack of population-based screening programs in China, and inadequate funding and access for mammograms [20], thereby making CBE a more affordable and practical option in clinical settings.

Limitations of this study include using a small convenience sample of recruited physicians from a city in western region of China which limits generalizability. Another limitation is that it is based on physicians' reports of their recommendations and practices; self-reported data were not validated with other data sources such as medical records or claims. It is also possible that the providers who answered the survey had an interest in breast health; thus, these results may actually be an overestimation of adherence to breast cancer screening practices in their patients.

In conclusion, physicians are an important informational source and access point for cancer screening. As this study's results indicate, physicians' beliefs influence their breast cancer screening recommendations and practices. Provider education regarding evidence-based breast cancer screenings and guidelines as well as future research exploring additional factors that may contribute to a lack of guideline awareness and adherence among physician populations are necessary. The study findings provide evidence that supports creating more effective strategies in empowering Chinese physicians and better preparing them to prescribe appropriate screening tests for their female clients in the future, a key factor which ultimately contributes to early detection and optimal prognosis for breast cancer.

\section{Acknowledgements}

The authors are extremely grateful to Chinese physicians who participated in the study and collaborators in China, and Shu-Yu Yen from Xi'An Cancer Rehabilitation Association.

\section{Source of Funding}

The project was supported by Eastern Michigan University Faculty Research Fellowship and the Susan G. Komen.

\section{Declaration Of Competing Interest}

The authors declare no conflict of interest.

\section{References}

1. Chen W, Zheng R, Baade PD, Zhang S, Zeng H, Bray F, Jemal A, Yu XQ, He J. Cancer statistics in China, 2015. CA: A Cancer Journal for Clinicians. 201601 25;66(2):115-132. https://doi.org/10.3322/caac.21338

2. National Office for Cancer Prevention and Control of the Chinese Ministry of Health. National survey on cancer mortality in China. . Beijing: The People's Health Press. 2010;:120-31.

3. Huang Z, Wen W, Zheng Y, Gao Y, Wu C, Bao P, Wang C, Gu K, Peng P, Gong Y, Zhang M, Xiang Y, Zhong W, Jin F, Xiang Y, Shu X, Beeghly-Fadiel A. Breast cancer incidence and mortality: trends over 40 years among women in Shanghai, China. Annals of Oncology. 2016 06;27(6):1129-1134. https://doi.org/10.1093/annonc/mdw069

4. Zheng S, Bai J, Li J, Fan J, Pang Y, Song Q, Huang R, Yang H, $\mathrm{Xu} \mathrm{F}, \mathrm{Lu}$ N, Qiao Y. The pathologic characteristics of breast cancer in China and its shift during 1999-2008: A nationalwide multicenter cross-sectional image over 10 years. International Journal of Cancer. 201204 17;131(11):26222631. https://doi.org/10.1002/ijc.27513

5. Sun Y, Zhao Z, Yang Z, Xu F, Lu H, Zhu Z, Shi W, Jiang J, Yao P, Zhu H. Risk Factors and Preventions of Breast Cancer. International Journal of Biological Sciences. 2017;13(11):1387-1397. https://doi.org/10.7150/ijbs.21635

6. National Clinical Research Center of Cancer at Tianjin Medical University Cancer Institute and Hospital. Breast cancer screening guideline for Chinese women. Cancer Biology \& Medicine. 2019;16(4):822-4. https://doi. org/10.20892/j.issn.2095-3941.2019.0321 
7. Wu T, Liu Y, Chung S. Improving Breast Cancer Outcomes among Women in China: Practices, Knowledge, and Attitudes Related to Breast Cancer Screening. International Journal of Breast Cancer. 2012;2012:1-8. https://doi. org/10.1155/2012/921607

8. Kwon HT, Ma GX, Gold RS, Atkinson NL, Wang MQ. Primary Care Physicians' Cancer Screening Recommendation Practices and Perceptions of Cancer Risk of Asian Americans. Asian Pacific Journal of Cancer Prevention. 201303 30;14(3):1999-2004. https://doi.org/10.7314/ apjcp.2013.14.3.1999

9. Su X, Ma GX, Seals B, Tan Y, Hausman A. Breast Cancer Early Detection among Chinese Women in the Philadelphia Area. Journal of Women's Health. 2006 06;15(5):507-519. https://doi.org/10.1089/jwh.2006.15.507

10. National Cancer Institute. National Survey of Primary Care Physicians' Recommendations \& Practice for Breast, Cervical, Colorectal, \& Lung Cancer Screening. Available at: https://healthcaredelivery.cancer.gov/screening_rp/ [Accessed: 17 June 2020].

11. Coughlin SS, Thompson T. Physician Recommendation for Colorectal Cancer Screening by Race, Ethnicity, and Health Insurance Status Among Men and Women in the United States, 2000. Health Promotion Practice. 2005 Oct;6(4):369378. https://doi.org/10.1177/1524839905278742

12. Coughlin SS. Physician Recommendation for Papanicolaou Testing Among U.S. Women, 2000. Cancer Epidemiology Biomarkers \& Prevention. 200505 01;14(5):1143-1148. https://doi.org/10.1158/1055-9965.epi-04-0559

13. Gilbert A, Kanarek N. Colorectal cancer screening: Physician recommendation is influential advice to Marylanders. Preventive Medicine. 2005 08;41(2):367-379. https://doi. org/10.1016/j.ypmed.2005.01.008

14. Ashford A, Gemson D, Sheinfeld Gorin SN, Bloch S, Lantigua R, Ahsan H, Neugut AI. Cancer screening and prevention practices of inner-city physicians. American Journal of Preventive Medicine. 2000 07;19(1):59-62. https://doi.org/10.1016/s0749-3797(00)00152-5

15. Corbelli J, Borrero S, Bonnema R, McNamara M, Kraemer K, Rubio D, Karpov I, McNeil M. Physician Adherence to U.S. Preventive Services Task Force Mammography Guidelines. Women's Health Issues. 2014 05;24(3):e313-e319. https:// doi.org/10.1016/j.whi.2014.03.003

16. Wenchi Liang, Wang JH, Chen M, Shibao Feng, Lee M, Schwartz MD, Pasick RJ, Mandelblatt JS. Developing and Validating a Measure of Chinese Cultural Views of Health and Cancer. Health Education \& Behavior. 200706 29;35(3):361375. https://doi.org/10.1177/1090198106294893

17. Lee-Lin F, Menon U, Nail L, Lutz KF. Findings from Focus Groups Indicating what Chinese American Immigrant Women Think about Breast Cancer and Breast Cancer Screening. Journal of Obstetric, Gynecologic \& Neonatal Nursing. 2012 09;41(5):627-637. https://doi.org/10.1111/ j.1552-6909.2012.01348.x

18. Craig C, Eby D, Whittington J. Care Coordination Model: Better Care at Lower Cost for People with Multiple Health and Social Needs. Available at: www.IHI.org [Accessed: 3 July 2020].

19. Fan L, Strasser-Weippl K, Li J, St Louis J, Finkelstein DM, Yu K, Chen W, Shao Z, Goss PE. Breast cancer in China. The Lancet Oncology. 2014 06;15(7):e279-e289. https://doi. org/10.1016/s1470-2045(13)70567-9

20. Wang F, Yu Z. Current status of breast cancer prevention in China. Chronic Diseases and Translational Medicine. 2015 03;1(1):2-8. https://doi.org/10.1016/j.cdtm.2015.02.003

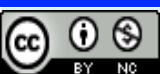

This work is licensed under a Creative Commons AttributionNon Commercial 4.0 International License. 